\title{
FGF-23 and hyperphosphatemia in dialysis dependent chronic kidney disease patients
}

\begin{abstract}
Introduction: Mineral bone disorder (MBD) is a major complication of chronic kidney disease (CKD). Aim was to evaluate Fibroblast Growth Factor (FGF-23); a phosphaturic hormone, identified as a regulator of calcium-phosphorus metabolism, in dialytic CKD patients.

Methods: Dialytic CKD (CKD stage 5) patients $(n=48)$ at recruitment were compared with age matched controls $(\mathrm{N}=66)$ and at six months for different indicators of bone metabolism and FGF-23 levels.

Results: Phosphorus $(\mathrm{p}=0.001)$, calcium-phosphorus product $(\mathrm{p}=0.001)$, intact Parathyroid hormone $(\mathrm{p}=0.001)$, intact-FGF-23 ( $\mathrm{p}=0.001)$ and C-terminal-FGF-23 ( $\mathrm{p}=0.001)$ levels in dialytic CKD patients were significantly higher than in their age matched controls. 1,25 $(\mathrm{OH})_{2} \mathrm{D}$ levels were almost nil in these patients and $25(\mathrm{OH}) \mathrm{D}$ were significantly lower $(\mathrm{p}=0.01)$ as compared to the controls. Phosphorus and intact-FGF-23 were significantly correlated (Spearman correlation $\mathrm{rs}=0.317, \mathrm{p}=0.028$ ) in dialytic CKD group. These CKD stage 5 patients were on regular calcium, vitamin D and phosphate binder treatment. Follow-up study demonstrated significant reduction in phosphorus $(\mathrm{p}=0.001)$, increase in $25(\mathrm{OH}) \mathrm{D}(\mathrm{p}=0.001)$ and $1,25(\mathrm{OH})_{2} \mathrm{D}$. iFGF-23 decreased marginally while there was no change in C-terminal FGF-23 levels at six months in dialytic CKD patients as compared to their recruitment levels.
\end{abstract}

Conclusion: Marked accumulation of inactive C-terminal FGF-23 might provide new insights in understanding the role of FGF-23 and hyperphosphatemia in CKD stage-5 patients.

Keywords: chronic kidney disease, fibroblast growth factor-23, hyperphosphatemia, mineral bone disease, secondary hyperparathyroidism
Volume 4 Issue 5 - 2017

\author{
Arun Halankar,' Sandhya Sivaraman, ${ }^{2}$ \\ KavitaShalia ${ }^{3}$ \\ 'Department of Nephrology, Sir H N Reliance Foundation \\ Hospital and Research Centre, India \\ ${ }^{2}$ Ph.D. Student,Sir H N Hospital and Research Centre, India \\ ${ }^{3} \mathrm{Sr}$ Scientist, Sir H N Medical Research Society, India
}

Correspondence: KavitaShalia, Sr Scientist,Sir H N Medical Research Society, Court House, LT Road, Mumbai 400002 , Maharashtra, India, Tel: 022 67673883; Fax: 022 67673898, Email Kavita.shalia@rfhospital.org

Received: March 25, 2017| Published: April 25, 2017

\section{Abbreviations}

CKD,chronic kidney disease; iFGF23, intact fibroblast growth factor-23; eGFR,estimated glomerular filtration rate; iPTH,intact parathyroid hormone; SHPT,secondary hyperparathyroidism; MDRD,modification of diet in renal disease; Ca,calcium; P, phosphorus; BALP,bone alkaline phosphatase

\section{Introduction}

Dialysis dependent chronic kidney disease (CKD) has become a worldwide public health problem. It is known to increase patient morbidity and mortality risks which can cause major economic strain on the health-care systems. A population based study has shown that the incidence of this end stage renal disease (ESRD) in India was 160 per million population (p.m.p.) in the year 2008. ${ }^{1}$ One of the most commonly encountered challenges in the management of dialysis dependent CKD patients is increasing levels of serum phosphorus secondary to a decrease in the glomerular filtration rate (GFR) less than $15 \%$. Hyperphosphatemia develops as a consequence of diminished phosphorus filtration and excretion with the progression of CKD. Decreased phosphorus excretion can initially be overcome by increased secretion of parathyroid hormone (PTH), which decreases reabsorption of phosphate in the proximal tubules by regulating $\mathrm{NaPi}-2 \mathrm{a}$ and $\mathrm{NaPi}-2 \mathrm{c}$ activities and thus induces an increase of urinary phosphate excretion ${ }^{2}$ According to the National
Kidney Foundation Kidney Disease Outcomes Quality Initiative (NKF-K/DOQI) classification, phosphorus levels are usually within normal range until the GFR falls below approximately $30 \mathrm{ml} / \mathrm{min}$, or CKD stage $4{ }^{3}$ In more advanced stages of CKD, the blunted urinary excretion of phosphorus can no longer keep pace with the obligatory intestinal phosphate absorption, resulting in hyperphosphatemia. ${ }^{4}$ Therefore, majority of dialytic CKD patients have significant hyperphosphatemia which further leads to several clinical conditions including cardiovascular diseases, bone diseases and secondary hyperparathyroidism (SHPT). ${ }^{5}$

PTH, by inducing the renal expression of 1-alpha-hydroxylase, increases production of active vitamin $\mathrm{D}$ metabolite, 1, 25-dihydroxyvitamin D 1, 25(OH)2 D/ Calcitriol/ Active Vitamin D, which can enhance intestinal phosphorus absorption. Apart from PTH and $1,25(\mathrm{OH})_{2} \mathrm{D}$, a phosphaturic hormone, Fibroblast Growth Factor (FGF-23) has recently been identified as a regulator of calciumphosphorus metabolism. FGF-23 is a bone derived hormone that regulates serum phosphate levels which is approximately $32-\mathrm{kDa}$ (251 amino acids). It was originally identified as a causative factor for autosomal dominant hypophosphataemic rickets. ${ }^{6}$ FGF-23 induces urinary phosphate excretion by decreasing expression of sodiumphosphate co-transporters on the brush border membrane of proximal tubules. ${ }^{7}$ In order to transmit its signal, the active FGF-23 (227 amino acids) forms a heterotrimer complex with receptor FGF1Rc and co- 
receptor Klotho. Between the $\mathrm{N}$ and $\mathrm{C}$ terminal domains there is a cleavage site at 179 amino acid that contains an RXXR motif for enzymes of the proconvertase-type of subtilisin or kexine type of the serine protease family.

In its dynamics, intact active FGF-23 is proteolytically cleaved at its $\mathrm{C}$ - terminal to produce inactive $\mathrm{C}$-terminal and $\mathrm{N}$ - terminal fragments. ${ }^{8}$ PTH and FGF-23 induce urinary phosphate excretion, however, their role differ for renal expression of 1-alpha-hydroxylase. FGF-23 inhibits 1-alpha-hydroxylase and stimulates 24-hydroxylase. Thus, PTH induces while FGF-23 suppresses renal production of 1 , $25(\mathrm{OH})_{2}$ D. ${ }^{9}$ It has been reported that in patients with $\mathrm{CKD}$, possibly to maintain neutral phosphorus balance, FGF-23 progressively increases as kidney function declines. ${ }^{10,11}$ This compensation by increased FGF23 , however, results in suppression of renal $1,25(\mathrm{OH})_{2} \mathrm{D}$ production which triggers the early development of SHPT..$^{10-13}$ Thus aim of the present study was to evaluate FGF-23 levels in addition to the conventional indicators of bone metabolism in dialytic CKD (stage 5) patients over a period of six months to explore the putative role of FGF-23 in CKD.

\section{Materials and methods}

\section{Enrollment of study population}

Study population was selected as per the inclusion and exclusion criteria set for the study. CKD patients aged between 18 to 70 years with or without any co-morbidity with estimated glomerular filtration rate (eGFR) less than $15 \mathrm{~mL} / \mathrm{min} / 1.73 \mathrm{~m}^{2}$; grouped under CKD stage 5 were enrolled. The eGFR for the staging of CKD was calculated using "Modification of Diet in Renal Disease" (MDRD) method." Patients found to be involved in any other trial or whose anticipated life expectancy was less than 6 months (e.g. because of a metastatic malignancy or terminal HIV disease), active infections or inflammatory disease (i.e., vascular-access infections and overt periodontal disease) were excluded. Also patient who were likely to conduct a kidney transplant program within 6 months of the recruitment into the study or unwilling to follow study protocol for any reason (including mental incompetence) or unable to provide informed consent or sign approved Consent Form were excluded from the study. Age matched healthy individuals to CKD patients were recruited. They were with no CKD or any other organic disease. They were confirmed healthy on the basis of their clinical history and routine biochemical tests.

\section{Ethical consideration}

All procedures performed in studies involving human participants were in accordance with the ethical standards of the Institutional Ethics Committee which follows the ethical standards laid down by the Indian Council of Medical Research's (ICMR's) ethical guidelines for biomedical research on human participants which includes the 1964 Helsinki declaration and its later amendments or comparable ethical standards. Patient Information Sheet (PIS) was explained to each patient in the language understood by them in the presence of the house doctor and patient's relatives. On agreeing to participate in the study, signature on PIS and Informed Consent (IC) was obtained from all individual participants included in the study before the blood collection

\section{Dialysis protocol}

CKD stage 5 patients $(\mathrm{N}=48)$ underwent hemodialysis either thrice or twice a week at an NGO, Nana PalkarSmrutiSamiti (Parel,
Mumbai). Dialysis was done using Fressinium 1.3 Dialyser and Polysulfone dialyzer membrane. Dialysate composition used was as per standard commercially available containing $3.5 \mathrm{mEq} / \mathrm{L}$ of $\mathrm{Ca}$ and the flow was maintained at 500-600 $\mathrm{ml} / \mathrm{minute}$. Blood samples were obtained just before starting hemodialysis sessions for renal profile analysis. Aliquots of serum and plasma were immediately obtained from the blood sample and then stored at $-80^{\circ}$ until further use.

\section{Recruitment of study population}

After the enrolment of patients in the study, blood and urine samples were collected for routine biochemical tests (Blood Urea Nitrogen (BUN), Creatinine, Calcium (Ca) Phosphorus (P) from serum and microalbuminuria from urine). Medication of vitamin $\mathrm{D}$ and calcium were stopped for fifteen days of these dialytic CKD patients. After this washout period, on 16th day which was considered as the first day of recruitment, blood and urine samples were again collected and routine biochemical tests were repeated. iPTH, 25(OH) D (total vitamin $\mathrm{D} /$ calcidiol), 1, 25(OH) 2 D, total and intact FGF-23 (iFGF23) and bone alkaline phosphatase (BALP) levels were also analyzed. These patients were again prescribed calcium and vitamin D treatment on the basis of the renal profile analyzed subsequent to the wash-out period of the above said medications. Thus, study population included 48 dialytic CKD patients and 66 controls. These dialytic CKD patients were then followed up for a period of six months.

\section{Routine pathological and research tests and medication protocol}

After recruitment, routine biochemical tests were repeated every month while iPTH, $25(\mathrm{OH}) \mathrm{D}$ and $1,25(\mathrm{OH})_{2} \mathrm{D}$ were repeated every three and six month and accordingly the doses of calcium and vitamin D were adjusted. Calcium tablets (Shelcal) $500 \mathrm{mg}$ once a day was given if serum $\mathrm{Ca}$ was less than $8.0 \mathrm{mg} / \mathrm{dl}$ and stopped if serum $\mathrm{Ca}$ was more than $11 \mathrm{mg} / \mathrm{dl}$. Rocalcitrol, $0.25 \mathrm{mg}$ once a day/twice a day was prescribed if serum $1,25(\mathrm{OH})_{2}$ D was low and stopped if serum 1 , $25(\mathrm{OH})_{2}$ D was above normal or serum Ca was more than $11.0 \mathrm{mg} / \mathrm{dl}$. Apart from these, on behalf of the doctor's discretion they were also given phosphate binders Lanthanum Carbonate (Fosbait 500mg) or Sevelamer (Sevacar $400 \mathrm{mg}$ ) was prescribed if serum P increased from $4.5 \mathrm{mg} / \mathrm{dl}$. With every $1.0 \mathrm{mg} / \mathrm{dl}$ increase in $\mathrm{P}$, the dose of phosphate binders was increased. Lanthanum is a "rare earth element" that has been shown to be effective in binding phosphate and consequently managing hyperphosphatemia ${ }^{14}$ while Sevelamer hydrochloride is a non-absorbable, synthetic ion-exchange polymer that binds phosphate and inhibits its absorption by the body. ${ }^{15}$ There was randomisation between the two phosphate binders on an equal basis. At six month Total FGF-3, iFGF-23 and BALP were repeated along with all other parameters. Two-dimensional Echocardiogram (2D-ECHO) and Bone Mineral Density (BMD) of CKD patients was carried out at recruitment and at six month.

\section{Methodology of research tests}

Serum levels of iPTH, were measured using immune-radiometric assay kits from DIA Source (hPTH-120 min-ITMs, KIP149*1, Belgium) which is a two-step immune-radiometric assay based on coated tube separation. Samples and calibrators were captured by goat antibodies specific to 1-34 PTH fragment (N-terminal) and subsequently detected by $125 \mathrm{I}$ labeled monoclonal antibody specific to $44-60 \mathrm{hPTH}$ fragments. Total Vitamin D $\left(25^{\mathrm{OH}} \mathrm{D}\right)$ and $1,25{ }^{\mathrm{OH}_{2}} \mathrm{D}$ were analyzed by Radioimmunoassay method (Kits from DiaSource, 25OH-Vitamin D total-RIA-CT, KIP1971 and 1, 
25 (OH) 2 -VIT.D-RIA-CT, KIP1929) wherein fixed amount of 125I labelled $25^{\mathrm{OH}} \mathrm{D}$ and $1,25^{\mathrm{OH}} 2 \mathrm{D}$ competes with respective vitamin present in serum for a fixed amount of antibody site immobilized on the wall of the polystyrene tube. Plasma iFGF-23 and Total FGF23 was measured using a two-step iFGF-23 and C terminal FGF-23 enzyme linked immunsorbent assay (ELISA) kit (Second generation ImmunotopicsInc, San Clemente, USA) respectively according to the manufacturer's protocol.

iFGF-23 ELISA assay had the antibodies that recognized the epitopes between $\mathrm{N}$-terminal and $\mathrm{C}$-terminal portion of the processing site of FGF-23, i.e. this kit recognized only the biologically active portion of FGF-23. Intact-FGF-23 values were expressed in $\mathrm{pg} / \mathrm{ml}$. In contrast, C-terminal FGF-23 assay detected both, the biological active portion i.e. iFGF-23 which was not cleaved and the C-terminal inactive fragment of FGF-23 which was produced after cleavage of active iFGF-23. Hence, the above C-terminal ELISA assay provided with the values of Total FGF-23 levels present in the circulation. C-terminal FGF-23 values were expressed in relative units (RU)/ $\mathrm{mL}$, and $1 \mathrm{RU} / \mathrm{mL}$ roughly equates to $2 \mathrm{pg} / \mathrm{mL}$ according to the manufacturer. ${ }^{16}$ The inactive C-terminal fragment levels were then derived by subtracting the levels of active iFGF-23 (pg/ml) from Total FGF-23 (pg/ml). The iFGF-23 assay showed an intra-assay coefficient of variation $(\mathrm{CV})$ of $5.8 \%$ and inter-assay $\mathrm{CV}$ of $8.9 \%$ and that of $\mathrm{C}$ terminal FGF-23 assay showed an intra-assay CV of $4.0 \%$ and interassay CV of $4.8 \%$. 2D Echocardiography or cardiac ultrasound was carried out to analyse the structure and function of the heart. Bone Mineral Density (BMD) of the Left Ventricular forearm (F), femoral neck (FN) and lumbar spine (LS) were also determined using dual energy X-ray absorptiometry at the time of recruitment and at the end of 6 month of CKD patients.

\section{Statistical analysis}

Measured variables as Mean \pm SD or median (25th/75th quartiles) were compared between patient groups and controls with the use of unpaired student's t test or Mann-Whitney $U$ test respectively and between two time intervals with the use of paired t test or Wilcoxon signed-rank test respectively. Correlations were studied by either Pearson or Spearman Correlation test. $\mathrm{p}<0.05$ was considered as statistically significant. Analyses were performed using statistical software SPSS (version 21.0, Chicago, IL).

\section{Results and discussion}

\section{Recruitment data}

Table 1 shows the demographic data of dialytic CKD patients at the time of the recruitment. Weight and BMI of the dialytic CKD patients were significantly low compared to the age matched controls (Table 1). BUN (5.21 fold) and creatinine (7.0 fold) of these CKD stage 5 patients were significantly $(\mathrm{p}=0.001)$ high as compared to controls (Table 2). Phosphorus $(50.8 \%, \mathrm{p}=0.001)$, calcium-phosphorus product $(52.3 \%, \mathrm{p}=0.001)$ and iPTH ( 8.4 fold, $\mathrm{p}=0.001)$ levels in dialytic CKD patients were significantly higher than in their age matched controls (Figure 1-3). 1,25(OH) $2 \mathrm{D}$ levels were almost nil in these patients and $25(\mathrm{OH}) \mathrm{D}$ were significantly lower $(32.5 \%, \mathrm{p}=0.01)$ as compared to the controls. Total FGF-23, iFGF-23 and C terminal FGF-23 were significantly $(\mathrm{p}=0.001)$ higher by $44.5,19.0$ and 49.7 fold respectively in dialytic CKD patients as compared to controls (Figure 4-6). The increase in the C-terminal FGF-23 by iFGF-23 in controls and patients were 4.7 and 12.4 fold respectively. As compared to the controls,
BALP levels were significantly higher $(2.27$ fold $127 \%, \mathrm{p}=0.001)$ in these CKD stage 5 patients (Figure 7). A positive correlation was observed between $\mathrm{P}$ and iFGF-23 (Spearman correlation, $\mathrm{rs}=0.317$, $\mathrm{p}=0.028$ ) in dialytic CKD group. In the present study, phosphate binders prescribed to the patients were either Lanthanum Carbonate (Fosbait $500 \mathrm{mg}$ ) or Sevelamer (Sevacar $400 \mathrm{mg}$ ). There was no significant difference in the phosphate or calcium phosphorus product levels observed when CKD patients were divided into two groups as per the phosphate binders used (Data not shown).

Table I Demographic Data

\begin{tabular}{|c|c|c|c|}
\hline $\begin{array}{l}\text { Demographic } \\
\text { Data }\end{array}$ & $\begin{array}{l}\text { Control } \\
(\mathrm{N}=66)\end{array}$ & $\begin{array}{l}\text { Recruitment } \\
\text { CKD Stage } 5 \\
(\mathrm{~N}=48)\end{array}$ & \\
\hline$M / F$ & $32 / 34$ & $31 / 17$ & $\begin{array}{l}\text { The chi-square statistic } \\
\text { is } 2.91 . p=.0879 . \text { NS }\end{array}$ \\
\hline Age (years) & $41.4 \pm 10.5$ & $42.6 \pm 12.4$ & NS \\
\hline Weight (kg) & $65.2 \pm 15.4$ & $55.4 \pm \mid 4.0$ & $\begin{array}{l}p=0.001 \\
15.0 \downarrow\end{array}$ \\
\hline $\begin{array}{l}\text { Body Mass } \\
\text { Index (BMI) } \\
(\mathrm{kg} / \mathrm{m} 2)\end{array}$ & $25.2 \pm 5.2$ & $22.3 \pm 4.72$ & $\begin{array}{l}\mathrm{p}=0.01 \\
1 \mathrm{I} .6 \% \downarrow\end{array}$ \\
\hline Smoking & - & $13(27 \%)$ & \\
\hline Alcohol & - & $21(44 \%)$ & \\
\hline Diabetes & - & 27 (56\%) & \\
\hline Hypertension & - & $26(54 \%)$ & \\
\hline
\end{tabular}

NS non-significant

Table 2 Biochemistry Data

\begin{tabular}{|c|c|c|c|}
\hline $\begin{array}{l}\text { Routine } \\
\text { Biochemical } \\
\text { Tests }\end{array}$ & $\begin{array}{l}\text { Control } \\
(\mathrm{N}=66)\end{array}$ & $\begin{array}{l}\text { Recruitment } \\
\text { CKD Stage } 5 \\
(N=48)\end{array}$ & \\
\hline $\begin{array}{l}\text { Blood Urea } \\
\text { Nitrogen (BUN) } \\
(\mathrm{mg} / \mathrm{dl})\end{array}$ & $\begin{array}{l}9.50 \\
(8 / 12)\end{array}$ & $\begin{array}{l}49.5 \\
(38 / 58.8)\end{array}$ & $\begin{array}{l}42 \mathrm{I} .0 \%(5.2 \mathrm{I} \text { fold }) \uparrow \\
P=0.00 \mathrm{I}\end{array}$ \\
\hline Creatinine (mg/dl) & $\begin{array}{l}1.0 \\
(1.0 / 1.0)\end{array}$ & $\begin{array}{l}7.0 \\
(6.0 / 8.0)\end{array}$ & $\begin{array}{l}600 \% \\
(7.0 \text { fold }) \uparrow \\
p=0.001\end{array}$ \\
\hline
\end{tabular}


Table Continues...

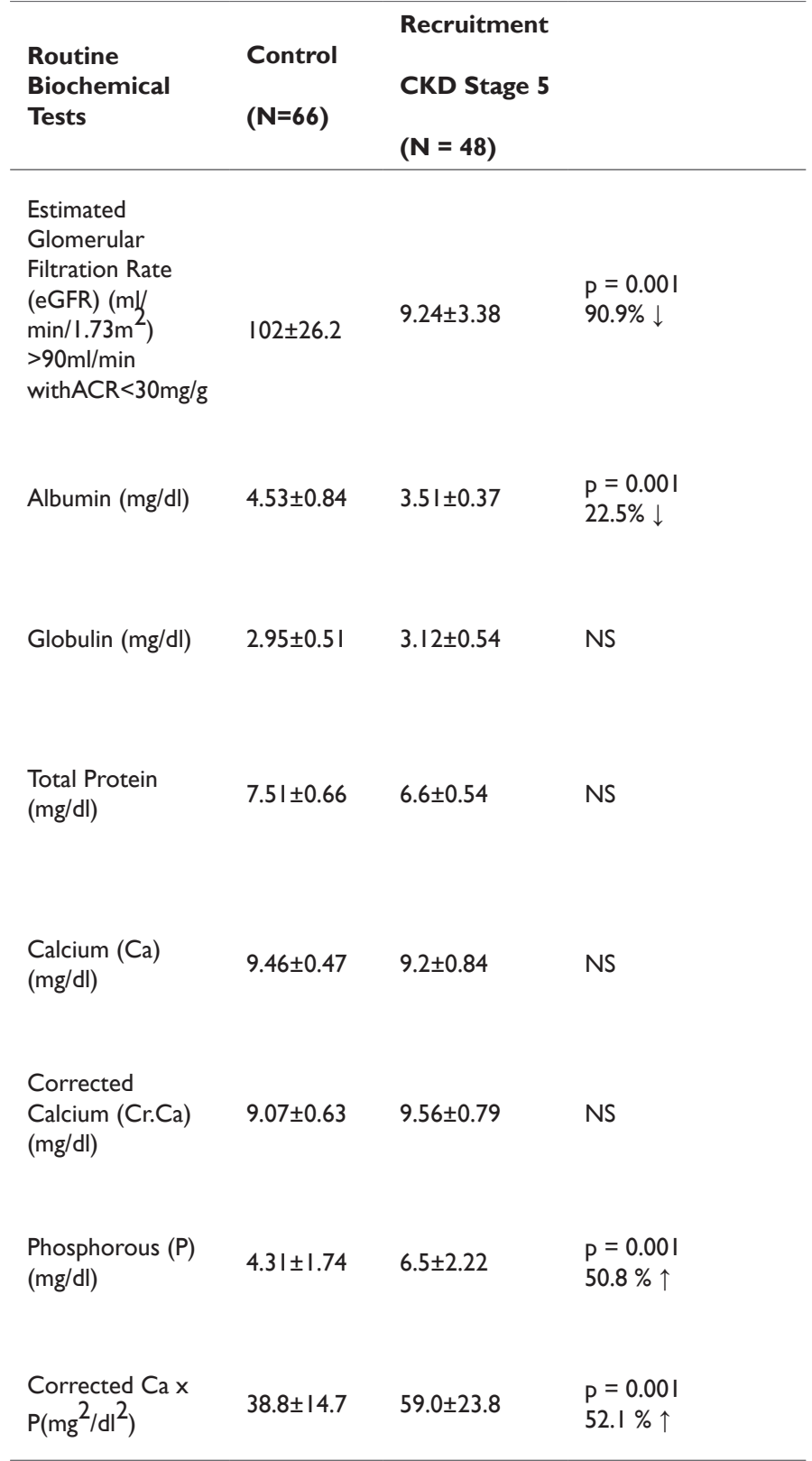

NS non-significant

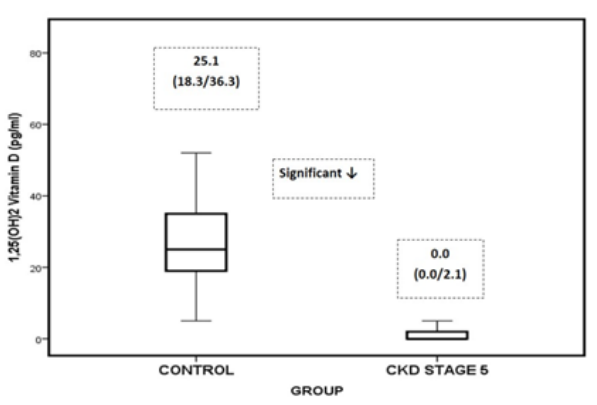

Figure 2I, $25(\mathrm{OH}) 2 \mathrm{D}$ (Active Vitamin D) Levels.

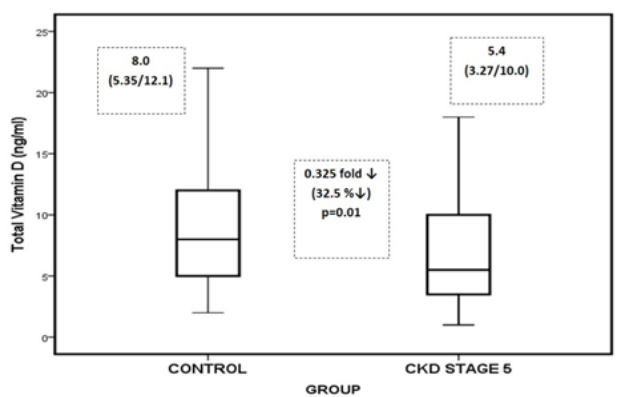

Figure $325(\mathrm{OH})$ D (Total Vitamin D) Levels.

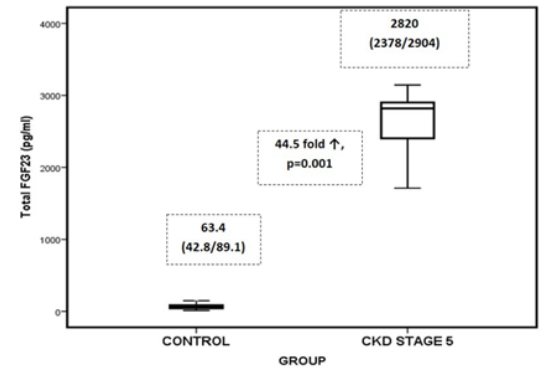

Figure 4Total FGF-23 Levels.

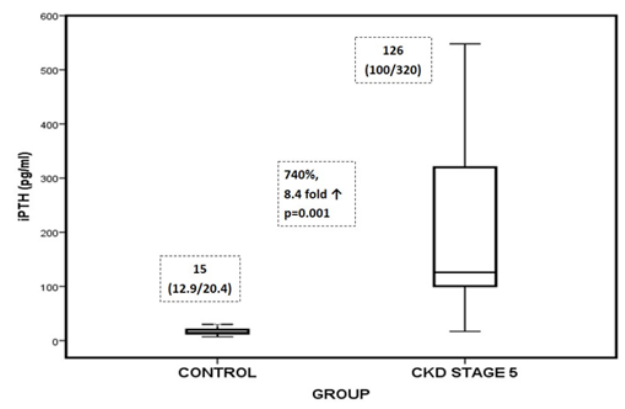

Figure I Intact-Parathyroid Hormone (iPTH) Levels.

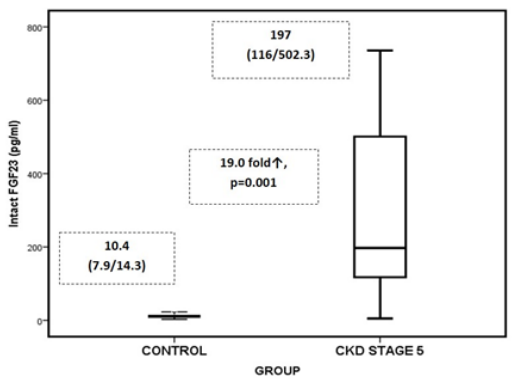

Figure 5 intact-FGF-23 (iFGF-23) Levels. 


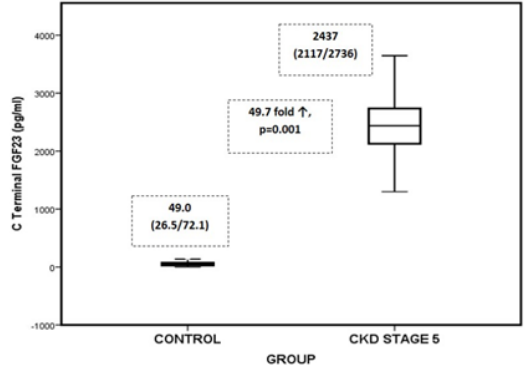

Figure 6 C-terminal FGF-23 Levels.

\section{Follow up data}

The demographic data of these patients at follow-up did not differ significantly from the time of recruitment (Data not shown). Renal profile of dialytic CKD patients at the end of 6 months follow up is depicted in Table 3. In these patients serum phosphorus $(31.0 \%$, $\mathrm{p}=0.001)$ and calcium phosphorus product $(27.6 \%, \mathrm{p}=0.001)$ decreased significantly at the end of six months as compared to baseline levels,. Total vitamin D i.e. $25(\mathrm{OH}) \mathrm{D}$ increased by 2.37 fold $(137 \%, \mathrm{p}=0.001)$ and median of $1,25(\mathrm{OH})_{2} \mathrm{D}$ increased from 0 to $5.9 \mathrm{pg} / \mathrm{ml}$ (Table 4) in dialytic CKD patients at six month as compared

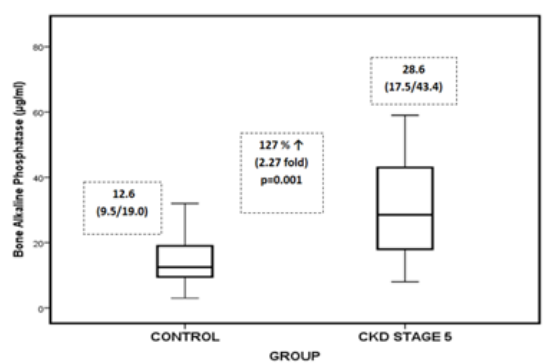

Figure 7Bone Alkaline Phosphatase (BALP) Levels.

to their recruitment levels. iFGF-23 decreased marginally $(11.7 \%$, $\mathrm{p}=0.01)$ while BALP reduced significantly $(45.8 \%, \mathrm{p}=0.001)$ and there was no change in iPTH, and C-terminal FGF-23 levels at six month in dialytic CKD patients from recruitment levels (Table 4). 2D Echocardiography data at the end of six months in dialytic patients showed significant decrease in the end diastolic volume (EDV) of $8.7 \%(\mathrm{p}=0.01)$ as compared to their recruitment data (Table 5). BMD expressed lower $\mathrm{t}$ score $(3.2 \%, \mathrm{p}=0.02)$ and $\mathrm{z}$ score $(8.4 \%, \mathrm{p}=0.02)$ at forearm and $\mathrm{z}$ score $(21 \%, \mathrm{p}=0.01)$ at femoral neck as compared to the recruitment data (Table 6).

Table 3 Six Month Follow up Biochemistry Data

\begin{tabular}{|c|c|c|c|}
\hline Routine Biochemical Tests & $\begin{array}{l}\text { Recruitment } \\
\text { CKD STAGE 5(N = 48) }\end{array}$ & $\begin{array}{l}6^{\text {th }} \text { Month Follow Up } \\
\text { CKD STAGE } 5(\mathrm{~N}=48)\end{array}$ & Significance \\
\hline Blood Urea Nitrogen (BUN) (mg/dl) & $\begin{array}{l}49.5 \\
(38.0 / 58.8)\end{array}$ & $\begin{array}{l}49.0 \\
(38.0 / 69.0)\end{array}$ & NS \\
\hline Creatinine $(\mathrm{mg} / \mathrm{dl})$ & $\begin{array}{l}7.0 \\
(6.0 / 8.0)\end{array}$ & $\begin{array}{l}8 \\
(6.0 / 9.0)\end{array}$ & NS \\
\hline $\begin{array}{l}\text { Estimated Glomerular Filtration Rate (eGFR) } \\
\left(\mathrm{ml} / \mathrm{min} / 1.73 \mathrm{~m}^{2}\right)>90 \mathrm{ml} / \mathrm{min} \text { withACR }<30 \mathrm{mg} / \mathrm{g}\end{array}$ & $9.01 \pm 3.20$ & $9.17 \pm 3.70$ & NS \\
\hline Albumin (mg/dl) & $3.5 I \pm 0.37$ & $3.58 \pm 0.32$ & NS \\
\hline Globulin (mg/dl) & $3.12 \pm 0.54$ & $3.13 \pm 0.86$ & NS \\
\hline Total Protein (mg/dl) & $6.61 \pm 0.54$ & $6.73 \pm 0.64$ & NS \\
\hline Calcium (Ca) (mg/dl) & $8.91 \pm 0.92$ & $9.22 \pm 0.88$ & NS \\
\hline Corrected Calcium (Cr.Ca) (mg/dl) & $9.52 \pm 0.81$ & $9.82 \pm 0.81$ & NS \\
\hline Phosphorous (P) (mg/dl) & $6.45 \pm 2.20$ & $4.45 \pm 1.26$ & $\begin{array}{l}p=0.001 \\
31.0 \% \downarrow\end{array}$ \\
\hline Corrected $\mathrm{Ca} \times \mathrm{P}\left(\mathrm{mg}^{2} / \mathrm{dl}^{2}\right)$ & $58.6 \pm 24.3$ & $42.4 \pm 14.8$ & $\begin{array}{l}P=0.001 \\
27.6 \% \downarrow\end{array}$ \\
\hline
\end{tabular}

NS non-significant 
Table 4Six Month Follow up Data Continued

$\begin{array}{ll}\text { Recruitment } & \text { 6 }^{\text {th Month }} \\ \text { CKD STAGE 5 } & \text { Follow Up } \\ (\mathbf{N}=48) & \text { CKD STAGE 5 } \\ & (\mathrm{N}=48)\end{array}$

\begin{tabular}{lll}
\hline Intact & & \\
Parathyroid & 126 & 120 \\
Hormone & $(100 / 320)$ & $(57.8 / 187)$
\end{tabular}

(iPTH) $(\mathrm{pg} / \mathrm{ml})$

$\begin{array}{llll}25(\mathrm{OH}) \mathrm{D} & 5.4 & 12.8 & 137 \% \\ (\mathrm{ng} / \mathrm{ml}) & (3.27 / / 0.0) & (9.5 / 18.3) & (2.37 \text { fold }) \uparrow, \\ & & \end{array}$

$\begin{array}{ll}\mathrm{l}, 25(\mathrm{OH}) 2 & 0.0 \\ \mathrm{D}(\mathrm{pg} / \mathrm{ml}) & (0.0 / 2.1)\end{array}$

$(0.0 / 2.1)$

$(3.25 / 9.57)$

Total

Fibroblast

Growth

Factor -23

(FGF-23)

$(\mathrm{pg} / \mathrm{ml})$

Intact

Fibroblast

Growth

Factor -23

(iFGF-23)

197

$(\mathrm{pg} / \mathrm{ml})$

CTerminal

Fibroblast

Growth

Factor -23

2820

$(2378 / 2904)$

2748

$(2512 / 2860)$

NS $\mathrm{P}=0.001$

(FGF-23)

(2117/2736)

2410

$(\mathrm{pg} / \mathrm{ml})$

Bone Alkaline

Phosphatase

(BALP) $(\mu g / L)$

28.6

$(17.4 / 43.4)$

15.5

$(10.5 / 23.4)$

$45.8 \% \downarrow$

$\mathrm{P}=0.00 \mathrm{I}$

NS non-significant

Table 5 Left Ventricle Function Data

\begin{tabular}{|c|c|c|c|}
\hline & $\begin{array}{l}\text { Recruitment } \\
\text { CKD STAGE } 5 \\
(N=48)\end{array}$ & $\begin{array}{l}6^{\text {th }} \text { Month } \\
\text { Follow Up } \\
\text { CKD STAGE } 5 \\
(N=48)\end{array}$ & $\begin{array}{l}\text { Significance } \\
\text { Level }\end{array}$ \\
\hline $\begin{array}{l}\text { Left Ventricular } \\
\text { Mass Index } 2 \\
\text { (LVMI) }\left(\mathrm{g} / \mathrm{m}^{2}\right)\end{array}$ & $\begin{array}{l}160 \\
(127 / 214)\end{array}$ & $\begin{array}{l}157 \\
(127 / 199)\end{array}$ & NS \\
\hline $\begin{array}{l}\text { End Diastolic volume } \\
\text { (EDV) }(\mathrm{ml})\end{array}$ & $\begin{array}{l}82.5 \\
(68.0 / 108)\end{array}$ & $\begin{array}{l}75.3 \\
(62.0 / 97.5)\end{array}$ & $\begin{array}{l}p=0.0048 .7 \\
\% \downarrow\end{array}$ \\
\hline
\end{tabular}

Table Continues.

\begin{tabular}{|c|c|c|c|}
\hline & $\begin{array}{l}\text { Recruitment } \\
\text { CKD STAGE } 5 \\
(\mathrm{~N}=48)\end{array}$ & $\begin{array}{l}6^{\text {th }} \text { Month } \\
\text { Follow Up } \\
\text { CKD STAGE } 5 \\
(N=48)\end{array}$ & $\begin{array}{l}\text { Significance } \\
\text { Level }\end{array}$ \\
\hline $\begin{array}{l}\text { End Systolic Volume } \\
(\text { ESV) }(\mathrm{ml})\end{array}$ & $\begin{array}{l}33.6 \\
(23.7 / 52.4)\end{array}$ & $\begin{array}{l}26.2 \\
(18.8 / 53.2)\end{array}$ & NS \\
\hline $\begin{array}{l}\text { LVEF Left Ventricular } \\
\text { Ejection Fraction } \\
\text { (LVEF) (\%) }\end{array}$ & $\begin{array}{l}55 \\
(55 / 60)\end{array}$ & $\begin{array}{l}55 \\
(55 / 60)\end{array}$ & NS \\
\hline $\begin{array}{l}\text { Stroke Volume (SV) } \\
(\mathrm{ml})\end{array}$ & $\begin{array}{l}46.2 \\
(41.3 / 58.4)\end{array}$ & $\begin{array}{l}45.2 \\
(37.5 / 58.5)\end{array}$ & NS \\
\hline
\end{tabular}

NS non-significant

Table 6Bone Mineral Densitometry Data

\begin{tabular}{|c|c|c|c|}
\hline & $\begin{array}{l}\text { Recruitment } \\
\text { CKD STAGE } \\
5(N=48)\end{array}$ & $\begin{array}{l}6^{\text {th }} \text { Month } \\
\text { Follow Up CKD } \\
\text { STAGE5 }(N=48)\end{array}$ & $\begin{array}{l}\text { Significance } \\
\text { Level }\end{array}$ \\
\hline & $\begin{array}{l}\text { Median } \\
\text { Percentiles } \\
25 / 75\end{array}$ & $\begin{array}{l}\text { Median } \\
\text { Percentiles 25/75 }\end{array}$ & \\
\hline $\begin{array}{l}\text { FOREARM } \\
\text { T Score SD }\left(\mathrm{g} / \mathrm{cm}^{2}\right)\end{array}$ & $\begin{array}{l}-3.1 \\
(-4.1 /-2.3)\end{array}$ & $\begin{array}{l}-3.2 \\
(-4.7 /-2.6)\end{array}$ & $\begin{array}{l}\mathrm{P}=0.02 \\
3.2 \% \downarrow\end{array}$ \\
\hline Z Score $S D\left(g / \mathrm{cm}^{2}\right)$ & $\begin{array}{l}-2.95 \\
(-4.07 /-1.9)\end{array}$ & $\begin{array}{l}-3.2 \\
(-4.7 /-2.6)\end{array}$ & $\begin{array}{l}P=0.02 \\
8.4 \% \downarrow\end{array}$ \\
\hline $\begin{array}{l}\text { FEMORAL NECKT } \\
\text { Score SD }\left(\mathrm{g} / \mathrm{cm}^{2}\right)\end{array}$ & $\begin{array}{l}-1.15 \\
(-2.2 /-0.52)\end{array}$ & $\begin{array}{l}-2.2 \\
(-2.95 /-1.9)\end{array}$ & NS \\
\hline Z Score $S D\left(g / \mathrm{cm}^{2}\right)$ & $\begin{array}{l}-1.15 \\
(-2.2 /-0.52)\end{array}$ & $\begin{array}{l}-1.4 \\
(-2.2 /-0.8)\end{array}$ & $\begin{array}{l}\mathrm{P}=0.01 \\
21.0 \% \downarrow\end{array}$ \\
\hline $\begin{array}{l}\text { LUMBAR SPINE } \\
\text { T Score SD }\left(\mathrm{g} / \mathrm{cm}^{2}\right)\end{array}$ & $\begin{array}{l}-2.2 \\
(-3.1 /-1.52)\end{array}$ & $\begin{array}{l}-1.9 \\
(-3.0 /-1.5)\end{array}$ & NS \\
\hline$Z$ Score SD $\left(\mathrm{g} / \mathrm{cm}^{2}\right)$ & $\begin{array}{l}-1.4 \\
(-2.2 /-0.72)\end{array}$ & $\begin{array}{l}-1.4 \\
(-2.2 /-0.45)\end{array}$ & NS \\
\hline
\end{tabular}

NOTE: In the general population T-score $\leq-2.5 \mathrm{SD}=\mathrm{OSTEOPOROSIS}$, T-score - I.0 TO -2.49 SD = OSTEOPENIA Z Score above -2.0 is considered normal acc. to International Society for Clinical Densitometry.

NS non-significant

\section{Discussion}

In the present study, it was observed that plasma FGF-23 levels; both intact as well as C-terminal increased significantly in dialytic CKD patients as compared to the controls. A similar line of observation has also been reported by Chathoth et al. ${ }^{17}$ and Hamano et al. ${ }^{18}$ Shimada et al. ${ }^{19}$ have reported that most of the elevated circulating FGF-23 in CKD is intact and biologically active in patients undergoing dialysis to maintain the phosphorus balance. Whereas Berndt et al. ${ }^{20}$ suggested that proteolytically generated inactive fragments retained the phosphaturic activity of intact hormone in kidney cells. However Goetz et al. ${ }^{21}$ provided in vitro and in vivo evidence that the isolated C-terminal FGF-23 domain antagonized the activity of the intact hormone by competing for the availability of the receptor complex and can be the portion that is present in higher concentration during the diseased condition. In the present study it was observed that rise in 
the levels of C-terminal fragments of FGF-23 was more as compared to that of iFGF-23 and there was significant increase in P levels in dialytic CKD patients. The above mentioned increase in the levels of C-terminal FGF-23 suggests reduced renal clearance causing marked accumulation of C-terminal fragments in chronic hemodialysis patients. According to the experimental evidence from Goetz et al. ${ }^{21}$ the increase in C-terminal FGF23 observed in the present study may interfere in the phosphaturic activity of the intact hormone causing significant increase in P levels at the dialytic stage of CKD patients.

SHPT and 1, $25(\mathrm{OH})_{2}$ D deficiency are common complications among the long-term dialytic CKD patients. ${ }^{22,23}$ SHPT is characterized by increased synthesis and secretion of PTH, mainly due to disturbances of calcium, phosphate and vitamin D metabolism. In addition, data suggests that FGF-23, plays a central role in the pathogenesis of SHPT by inhibiting 1 alpha hydroxylase which results in the reduction of calcitriol. ${ }^{12,13}$ In agreement with the above findings, a significant reduction in the 1, $25(\mathrm{OH})_{2}$ D levels and significant increase in the levels of iPTH was observed in the present study. Hyperphosphatemia is considered a potent contributing stimulus for the development of SHPT, metastatic calcifications and renal osteodystrophy. ${ }^{5}$ Thus managing phosphate levels in dialysis patients is a multi-interrelated task, involving the indispensable action of FGF-23, serum PTH and vitamin D.

However, optimal phosphate control in dialysis patients is extremely challenging. ${ }^{24}$ Despite the significant increase in the levels of iPTH and phosphaturic hormone FGF-23, hyperphosphatemia were observed in CKD stage 5 patients. These dialysis patients were thus prescribed with phosphate binders and followed up for a period of six months. Multiple clinical studies have demonstrated that Sevelamer Hydrochloride lowers serum phosphorus levels among patients with ESRD and is generally well tolerated. ${ }^{25,26}$ Apart from Sevelamer, several clinical trials have shown that Lanthanum is another effective and well tolerated phosphate binder among healthy volunteers as well as hemodialysis patients. ${ }^{27,28}$ In the present study there was randomisation between the two phosphate binders among the patients. These patients were also provided with calcium carbonate and calcitriol tablets depending on their serum calcium and vitamin D levels. Calcium carbonate has been used extensively worldwide since the early 1980s because of its efficacy, tolerability, and affordability. ${ }^{29,30}$

Thus at six month follow-up, after above said treatment, a significant decrease in serum $\mathrm{P}$ levels, Ca-P levels, marginal drop in iFGF-23 levels and significant increase in 1, $25(\mathrm{OH})_{2}$ D as compared to the baseline levels was observed in these $\mathrm{CKD}$-stage 5 patients. The drugs, however, are more expensive and this is a significant factor in a country like India, where cost is a major deciding factor in patient's treatment. Disruption in mineral metabolism occur at early stages of $\mathrm{CKD}$, which further increases as the disease progresses causing alterations in bone mass, bone turnover, mineralization and bone health leading to severe osteoporosis and marked risk of fractures. ${ }^{31}$ Till date several studies have reported deterioration of BMD in CKD and association of FGF-23 with vascular calcification. ${ }^{32,33}$ Although damage to Bone was noted from the BMD data of forearm and femoral neck in the present study, inverse correlation of BMD data with FGF23 was not observed.

Cardiovascular disease is a major complication found in dialytic CKD patients. Cardiac assessment by echocardiography is non- invasive, inexpensive to perform and generates detailed information on left ventricular function (LVF) i.e. measures of its function during systole and diastole and on gross cardiac anatomy, such as left ventricular mass (LVM). CKD patients have been reported to have high prevalence of left ventricular dysfunction. ${ }^{34,35}$ In the present study echocardiographic parameters were evaluated at recruitment and at six month in these CKD patients wherein significant decrease in the end-diastolic volume (EDV) was observed at six month. EDV is the amount of blood in the ventricles just before systole and if it increases then eventually may cause $\mathrm{LVH}$, pulmonary congestion and edema. An association between FGF23 and cardiac hypertrophy and systolic dysfunction has been observed among patients without CKD as well as those with CKD after multivariate adjustment. ${ }^{36}$ However, present study did not reveal direct association of FGF-23 with LV function, improvement in LV function in terms of reduction in EDV was observed at six month of follow-up of the study where patients were monitored for P levels and for its control.

\section{Conclusion}

Thus in the present study in the dialytic CKD patients as compared to controls, serum P, C-terminal and iFGF-23 levels were found to increase significantly. Extensive rise of C-terminal FGF-23 as compared to the iFGF-23 suggested a marked accumulation of C-terminal fragments in chronic hemodialysis patients. SHPT and calcitriol deficiency were another complications which were found to predominate in the dialytic patients. Although, treatment with phosphate binders was effective in reducing $\mathrm{P}$ and $\mathrm{Ca}-\mathrm{P}$ levels, the extent of rise in levels of iPTH and C-terminal FGF-23 remained same at the end of the six month. Due to drop out of patients, the study was restricted to the numbers indicated for patients and followup period of six months. Remarkable increase in inactive C-terminal FGF-23 may provide new insights into the pathophysiologic effects of FGF-23 on phosphate homeostasis and on clinical management of CKD patients on dialysis.

\section{Acknowledgement}

Authors would like to acknowledge Sir H N Medical Research Society, Mumbai for financial support. Sir H N Hospital and Research Centre, Mumbai and Nana PalkarSmrutiSamiti (Parel, Mumbai) for permitting the recruitment of the patients for the study. Authors also acknowledge assistance from MsCharutaGodbole and Ms Poonam Pawar for the project.

\section{Conflicts of interest}

None.

\section{References}

1. Modi G, Jha V. Incidence of ESRD in India. Kidney International. 2011;79(5):573.

2. Slatopolsky E, Gradowska L, Kashemsant C, et al. The control of phosphate excretion in uremia. J Clin Invest. 1966;45(5):672-677.

3. National Kidney Foundation. K/DOQI clinical practice guidelines for chronic kidney disease: evaluation, classification, and stratification. $\mathrm{Am}$ J Kidney Dis. 2002;39(2 Suppl 1):S1-266.

4. Bricker NS, Slatopolsky E, Reiss E, et al. Calcium, phosphorus and bone in renal disease and transplantation. Arch Intern Med. 1969;123(5):543-553. 
5. Block GA, Hulbert-Shearon TE, Levin NW, et al. Association of serum phosphorus and calcium $\times$ phosphate product with mortality risk in chronic hemodialysis patients: A national study. Am J Kidney Dis. 1998;31(4):607-617.

6. ADHR Consortium. Autosomal Dominant Hypophosphataemic Rickets is Associated with Mutations in FGF-23. Nat Genet. 2000;26(3): 345-348.

7. Saito H, Kusano K, Kinosaki M, et al. Human fibroblast growth factor-23 mutants suppress Na-dependent phosphate cotransport activity and 1 alpha, 25-dihydroxyvitamin D3 production. $J$ Biol Chem. 2003;278(4):2206-2011.

8. Kurosu H, Ogaw Y, Miyosh M, et al. Regulation of fibroblast growth factor-23 signaling by klotho. J Boil Chem. 2006;281(10):6120-6123.

9. Shimada T, Hasegawa H, Yamazaki Y, et al. FGF-23 is a potent regulator of vitamin D metabolism and phosphate homeostasis. J Bone Miner Res. 2004;19(3):429-435

10. Shigematsu T, Kazama JJ, Yamashita T, et al. Possible involvement of circulating fibroblast growth factor 23 in the development of secondary hyperparathyroidism associated with renal insufficiency. Am J Kidney Dis. 2004;44(2):250-256.

11. Gutierrez O, Isakova T, Rhee E, et al. Fibroblast growth factor-23 mitigates hyperphosphatemia but accentuates calcitriol deficiency in chronic kidney disease. J Am Soc Nephro. 2005;116(7):2205-2215.

12. Komaba H, Fukagawa M. FGF-23-parathyroid interaction: implications in chronic kidney disease. Kidney Int. 2010;77(4):292-298.

13. Gutierrez OM. Fibroblast growth factor 23 and disordered vitamin D metabolism in chronic kidney disease: updating the "trade-off" hypothesis. Clin J Am Soc Nephrol. 2010;5(9):1710-1716.

14. Albaaj F, Hutchison AJ. Lanthanum carbonate for the treatment of hyperphosphataemia in renal failure and dialysis patients. Expert Opin Pharmacother. 2005;6:319-328.

15. Hutchison AJ, Smith CP, Brenchley PE. Pharmacology, efficacy and safety of oral phosphate binders. Nat Rev Nephrol. 2011;7(10):578-589.

16. Devaraj S, Duncan-Staley C, Jialal I. Evaluation of a method for fibroblast growth factor-23: a novel biomarker of adverse outcomes in patients with renal disease. Metab Syndr Relat Disord. 2010;8(6):477-482.

17. Chathoth S, Al-Mueilo S, Cyrus C, et al. Elevated Fibroblast Growth Factor 23 Concentration: Prediction of Mortality among Chronic Kidney Disease Patients. Cardiorenal Med. 2015;6(1):73-82.

18. Hamano T, Nakano C, Obi Y, et al. Fibroblast growth factor 23 and 25-hydroxyvitamin D levels are associated with estimated glomerular filtration rate decline. Kidney Int Suppl. 2011;3(5):469-475.

19. Shimada T, Urakawa I, Isakova T, et al. Circulating Fibroblast Growth Factor 23 in Patients with End-Stage Renal Disease Treated by Peritonea Dialysis Is Intact and Biologically Active. J Clin Endocrinol Metab. 2010;95(2):578-585.

20. Berndt TJ, Craig TA, McCormick DJ, et al. Biological activity of FGF-23 fragments. Pflugers Archiv. 2007;454(4):615-623.
21. Goetz R, Nakada Y, Hu MC, et al. Isolated C-terminal tail of FGF23 alleviates hypophosphatemia by inhibiting FGF23-FGFR-Klotho complex formation. Proc Natl Acad Sci USA. 2010;107(1):407-412.

22. Drüeke TB. Cell biology of parathyroid gland hyperplasia in chronic renal failure. J Am Soc Nephrol. 2000;11(6):1141-1152.

23. Fukagawa M, Komaba H, Onishi Y, et al. Mineral metabolism management in hemodialysis patients with secondary hyperparathyroidism in Japan: baseline data from the MBD-5D. Am J Nephrol. 2011;33(5):427-437.

24. Ketteler M, Biggar PH. Use of phosphate binders in chronic kidney disease. Curr Opin Nephrol Hypertens. 2013;22(4):413-420.

25. Chertow GM, Burke SK, Raggi P, et al. Treat to Goal Working Group: Sevelamer attenuates the progression of coronary and aortic calcification in hemodialysis patients. Kidney Int. 2002;62(1):245-252.

26. Slatopolsky EA, Burke SK, Dillon MA. RenaGel, a nonabsorbed calcium- and aluminum free phosphate binder, lowers serum phosphorus and parathyroid hormone. Kidney Int. 1999;55(1):299-307.

27. Soriano S, Ojeda R, Rodríguez M, et al. The effect of phosphate binders, calcium and lanthanum carbonate on FGF23 levels in chronic kidney disease patients. Clin Nephrol. 2013;80(1):17-22.

28. Sac M, Fosrenol. (lanthanum carbonate) is well tolerated in patients requiring hemodialysis: Results of a phase I clinical trial (Abstract). $J A m$ Soc Nephrol. 2002;13:386.

29. Meyrier A, Marsac J, Richet G. The influence of a high calcium carbonate intake on bone disease in patients undergoing hemodialysis. Kidney Int. 1973;4(2):146-153.

30. Slatopolsky E, Weerts C, Lopez-Hilker S, et al. Calcium carbonate as a phosphate binder in patients with chronic renal failure undergoing dialysis. $N$ Engl J Med. 1986;315(30):157-161.

31. Myong JP, Kim HR, Koo JW, et al. Relationship between bone mineral density and moderate to severe chronic kidney disease among general population in Korea. J Korean Med Sci. 2013;284:569-574.

32. Diniz H, Frazão JM. The role of fibroblast growth factor 23 in chronic kidney disease-mineral and bone disorder. Nefrologia. 2013;33(6):835-844.

33. Touissant ND, Lau KK, Strauss BJ, et al. Associations between vascular calcification, arterial stiffness and bone mineral density in chronic kidney disease. Nephrol Dial Transplant. 2008;23(2):586-593.

34. Sarmento-Dias M, Santos-Araújo C, Poínhos R, et al. Fibroblast growth factor 23 is associated with left ventricular hypertrophy, not with uremic vasculopathy in peritoneal dialysis patients. Clin Nephrol. 2016;85(3):135-141.

35. Nitta K, Iimuro S, Imai E, et al. Risk factors for increased left ventricular hypertrophy in patients with chronic kidney disease. Clin Exp Nephrol. 2013;17(5):730-742.

36. Tanaka S, Fujita S-i, Kizawa S, et al. Association between FGF23, $\alpha$-Klotho, and Cardiac Abnormalities among Patients with Various Chronic Kidney Disease Stages. PLoS ONE. 2016;11(7):e0156860. 